\title{
Comparison of Respiratory Parameters of Physically Disabled and Healthy Children
}

Rasmi MUAMMER', Seda BAKTIR², Kiymet MUAMMER ${ }^{3}$

${ }^{1}$ Department of Physiotherapy and Rehabilitation, Yeditepe University Faculty of Health Sciences, Istanbul, Turkey

${ }^{2}$ Department of Physiotherapy and Rehabilitation, Istanbul University Faculty of Health Sciences, Istanbul, Turkey

${ }^{3}$ Department of Cardiopulmonary Physiotherapy and Rehabilitation, Istanbul University Instution of Cardiology, Istanbul, Turkey

\section{ABSTRACT}

Objective: The aim of this study was to compare the respiratory parameters of physically disabled and healthy children.

Methods: The study included 25 children. Of these children, 13 were physically disabled and 12 were healthy children. The BTL-08 spirometry device was used for measuring the respiratory values of the children. The gross motor function classification system (GMFCS) and manual ability classification system (MACS) levels were determined.

Results: A statistically significant difference was found between the respiratory parameters of physically disabled and healthy children in relation to the restrictive patterns $(\mathrm{p}<0.001)$. The values of forced vital capacity $(\% \mathrm{FVC})$ were found to be better in children with GMFCS level 2 and lower than children with level 3 and above $(\mathrm{p}<0.05)$.

Conclusion: In addition to the rehabilitation program for physically disabled children, a pulmonary rehabilitation program aiming to conduct respiratory training and increase the respiratory capacity would be useful.

Keywords: Disability, pulmonary rehabilitation, respiratory parameters

\section{Introduction}

A disabled individual is the one who has difficulties in fitting into society and meeting daily needs and who needs protection, care, rehabilitation, counseling, and support services because of having lost his/her physical, mental, emotional, and social abilities due to any congenital or acquired reason to varying degrees (1). In disabled children, respiratory system infections and decreased pulmonary functions are the most important causes of morbidity and mortality. The incidence of pulmonary complications is quite high and it is the most frequent cause of hospitalization. Recurrent pulmonary problems affect both the state of health and quality of life to a great extent. However, the ability to prevent and treat respiratory complications is extremely important for disabled children (2-5). The causes of respiratory problems in disabled children include immobilization, secondary contractures, peripheral and respiratory muscle weakness, spinal and thoracic deformities, ineffective cough, gastro-esophageal reflux, dysphagia and attacks, mucociliary transport dysfunction, malnutrition, development disorder, muscular tone diseases, congenital anomalies, and cardiac anomalies (3, 6-9). The aim of our study was to determine the respiratory parameters of disabled children and to compare them with healthy children.

\section{Methods}

The study included physically disabled and healthy children. The disabled children were chosen among those who were diagnosed by a specialist and referred to special education centers by local counseling and research centers for treatment and who were continuing this treatment. The children who were mentally disabled, had a diagnosis of a respiratory problem, were younger than 6 years old, and were thought to be unable to complete the test were excluded from the study. The BTL08 spirometry device (Digitex Medical Systems, United Kingdom) was used to measure the respiratory values of the chil-

Address for Correspondence: Rasmi Muammer; Department of Physiotherapy and Rehabilitation, Yeditepe University Faculty of Health Sciences, Istanbul, Turkey. Phone: +90 2165780000 (3186) E-mail: rasmymuammar@yahoo.com 
dren. During the test, the child was given in straight sitting position, in the way that the pelvis was as neutral as possible. For teaching, motivating, and encouraging the children, what he/she was expected to do was explained and demonstrated by giving examples before the test. A different mouthpiece was used for each child to maintain hygienic conditions. The nose was closed with a clip. Inspiration and expiration circuits were repeated for at least three times for each child, and the best results were recorded. Moreover, the functional and manual ability levels of disabled children were evaluated using the Gross Motor Function Classification System (GMFCS) and Manual Ability Classification System (MACS).

Our study was planned as a graduation research in the Department of Physiotherapy and Rehabilitation, Faculty of Health Sciences, Yeditepe University. Therefore, ethics committee approval was not received. Before the study, written informed consents were obtained from the parents of children who participated in the study.

\section{Statistical analysis}

For the statistical analysis of the data, the Statistical Package for the Social Sciences (SPSS) 22 analysis software (IBM, USA Partner Company: AIMS Analytical Information Management Solutions, Software Training Consulting Corp. Istanbul, Turkey) was used. Demographic data of the groups were specified with arithmetic mean and standard deviation. Mann-Whitney's U-test was employed for comparing the respiratory parameters of both groups.

\section{Results}

The disabled group consisted of three patients with neuromuscular disease and 10 patients with cerebral palsy. Six children with cerebral palsy were quadriparetic, 2 were right hemiparetic, and 2 were left hemiparetic.

The age, height, and weight averages of the disabled group were $12.38 \pm 4.02$ years, $141.62 \pm 19.07 \mathrm{~cm}$, and $37.77 \pm 14.28$ $\mathrm{kg}$, respectively. The averages of the healthy group were
$12.41 \pm 3.55$ years, $144.42 \pm 15.41 \mathrm{~cm}$, and $38.25 \pm 10.23 \mathrm{~kg}$, respectively. No statistically significant difference was found between two groups with respect to age, height, and weight ( $p>0.05$ ). The comparison of the respiratory parameters of the physically disabled children and healthy children showed a significant difference in terms of restrictive patterns $(\mathrm{p}<0.05)$. It was observed that maximum mid-expiratory flow (MMEF) and peak expiratory flow (PEF) values were lower in the disabled children and compared with the healthy group, a significant difference was found between two groups $(\mathrm{p}<0.05)$ (Table 1). Obstructive patterns were not observed in both groups. According to GMFCS in the disabled group, a significant difference was found between them when forced vital capacity values (\%FVC) with level 2 and below and level 3 and above were compared $(p<0.05)$ (Table 2). On the other hand, when \%FVC values with level 2 and below and level 3 and above were compared according to MACS, no significant difference was found between them ( $>$ >0.05) (Table 2).

\section{Discussion}

Proper respiratory function depends on correct breathing patterns, correct and effective coughing, and the ability to determine and to interfere respiratory tract infection. In disabled individuals who find it difficult or impossible to communicate, the problems continue for a long time. This makes the current situation more complex. Respiratory tract infections and respiratory complications are common among disabled children. A low level of activity, insufficient control of muscular function, spinal deformities, thoracic deformities, and weak respiratory muscles prevent performing exercises for deep and adequate respiration. These conditions make the excretion of mucus with ineffective coughing more difficult. Because of a difficulty in swallowing, the excretion of materials in the airway also becomes difficult. Poor nutrition makes the situation more difficult. All these conditions lead to the restriction of the lung functions and unbalanced lung expansion (2-5). Respiratory infection and decreased pulmonary functions influence both health state and quality of life to a

Table 1. Comparison of respiratory parameters between two groups

\begin{tabular}{|c|c|c|c|c|c|c|}
\hline & $\begin{array}{c}\text { Disabled } \\
\text { Group (n:13) }\end{array}$ & $\begin{array}{l}\text { Healthy Group } \\
\text { (n:12) }\end{array}$ & $\begin{array}{l}\text { Mean } \\
\text { Rank }\end{array}$ & $\begin{array}{l}\text { Total } \\
\text { Rank }\end{array}$ & $\mathbf{z}$ & $\mathbf{p}$ \\
\hline$\% F V C$ & 7.69 & 18.75 & 100.00 & 225.00 & 3.75 & 0.00 * \\
\hline$\% \mathrm{FEV}_{1}$ & 7.31 & 19.17 & 95.00 & 230.00 & 4.02 & 0.00 * \\
\hline$\% \mathrm{FEV}_{1} / \mathrm{FVC}$ & 14.77 & 11.08 & 192.00 & 133.00 & -1.31 & 0.22 \\
\hline PEF & 7.85 & 18.58 & 102.00 & 223.00 & -3.64 & $0.00^{*}$ \\
\hline MEF 75 & 7.85 & 18.58 & 102.00 & 223.00 & -3.64 & 0.00 * \\
\hline MEF 50 & 8.23 & 18.17 & 107.00 & 218.00 & -3.37 & $0.00^{*}$ \\
\hline MEF 25 & 9.54 & 16.75 & 124.00 & 201.00 & -2.45 & $0.01^{*}$ \\
\hline
\end{tabular}


Table 2. Comparison of \%FVC values at level 2 and below and at level 3 and above according to GMFCS and MACS

\begin{tabular}{|c|c|c|c|c|c|}
\hline GMFCS & $\mathbf{n}$ & $\begin{array}{c}\text { Mean } \\
\text { rank }\end{array}$ & $\begin{array}{l}\text { Total } \\
\text { rank }\end{array}$ & $\mathbf{Z}$ & P \\
\hline Level 2 and below & 7 & 9.29 & 65 & -2.28 & $0.02 *$ \\
\hline $\begin{array}{l}\text { Level } 3 \text { and above } \\
\text { MACS }\end{array}$ & 6 & 4.33 & 26 & & \\
\hline Level 2 and below & 7 & 8.86 & 62 & -1.85 & 0.06 \\
\hline Level 3 and above & 6 & 4.83 & 29 & & \\
\hline
\end{tabular}

great extent. At the beginning of our study, it was planned to include more disabled children in accordance with the inclusion criteria. However, some children were excluded from the study because of some reasons such as inability to blow crying, inability to stay in the appropriate position, and fear. In our study, the measurement values of all respiratory parameters were found to be significantly lower in physically disabled children than in healthy children. In terms of $\% \mathrm{FVC}$ values in the disabled group, 6 children had an advanced restrictive pattern, 3 had a moderate restrictive pattern, 2 had a mild restrictive pattern, and 2 had a normal pattern.

In patients with cerebral palsy, respiratory dysfunctions such as recurrent pneumonia, atelectasia, bronchiectasis, sleep apnea, chronic obstructive pulmonary disease, and restrictive lung disease are seen at a high level (10-12). It is known that respiratory dysfunction is the leading reason for death in patients with cerebral palsy. Despite this fact, respiratory dysfunction has not been handled sufficiently in severe cases because of the lack of cooperation $(12,13)$. In our study, the $\% \mathrm{FVC}$ values of children with level 2 and below and with level 3 and above according to GMFCS were compared, and children with higher levels displayed a statistically significant difference. A low level of pulmonary capacity and respiratory muscle weakness are seen in children with cerebral palsy who demonstrate low motor function. Kwon et al. (14) examined respiratory function tests in 49 children with cerebral palsy at level 3 and below according to GMFCS. They reported that the scores for the values of FVC, forced expiratory volume in the first second (FEV1), slow vital capacity (SVC), maximal inspiratory pressure (MIP), and maximal expiratory pressure (MEP) were lower at level 3 than at level 1 and level 2. In some studies, respiratory function was evaluated considering the type of cerebral palsy. It was found that children with spastic diplegic cerebral palsy had lower respiratory parameters than children with spastic hemiplegic cerebral palsy. Depending on the type of disability, biomechanical insufficiencies, weak respiratory muscles, and low volumetric ventilation affect respiratory mechanism (15). Although no statistically significant difference was found between children with level 2 and below and with level 3 and above with respect to \%FVC values according to MACS, the values were higher in children with better levels. In the literature review, no study evaluating the relationship between MACS and respiratory parameters was encountered. However, the activation of the muscles in the upper body with the movements of the upper extremities suggests that it has a positive contribution to the respiratory mechanism. The development of a thoracic respiratory pattern depends on successful segmental rolling activity and normal movement control of the head and the upper extremities. With the development of normal motor control in these body segments, the combination of thoracic and abdominal respiratory patterns also develops (16).

In the evaluation of $\% \mathrm{FVC}$ values in healthy children, only one child displayed a mild restrictive pattern. No obstructive pattern was observed in the groups.

\section{Conclusion}

In conclusion, we suggest that pulmonary rehabilitation programs should be implemented to provide respiratory training and increase respiratory capacity in disabled children in addition to the rehabilitation process because respiratory states can be affected by disability in this population.

Informed Consent: Written informed consent was obtained from patient/ patients who participated in this study.

Peer-review: Externally peer-reviewed.

Author Contributions: Concept - R.M.; Design - R.M., S.B.; Supervision R.M., K.M.; Funding - R.M., S.B., K.M.; Materials - R.M.; Data Collection and/or Processing - S.B.; Analysis and/or Interpretation - R.M., K.M.; Literature Review - S.B.; Writer - R.M., S.B.; Critical Review - K.M.

Conflict of Interest: The authors declared no conflict of interest.

Financial Disclosure: The authors declared that this study has received no financial support.

\section{References}

1. T.C. Sosyal hizmetler ve çocuk esirgeme kurumu genel müdürlüğü. Özürlülerin bakımı, rehabilitasyonu ve aile danışmanlığı. Yönetmelik 2010.

2. Barclay L, Lie D. Intrapulmonary percussive ventilation may be helpful in adolescents with neuromuscular disease. Arch Pediatr Adolesc Med 2005; 159: 526-31. [CrossRef]

3. Braverman JM. Airway clearance dysfunction associated with cerebral palsy: an overview. Advanced Respiratory 2001.

4. Doull I. Respiratory disorders in down's syndrome: overview with diagnostic and treatment options. Respiratory Disorders (General). Royal Society of Medicine Conference 2001.

5. Evans PM, Evans SJ, Alberman E. Cerebral palsies: why we must plan for survival. Arch Dis Child 1990; 65: 1329-33. [CrossRef]

6. Dempsey JA, Romer L, Rodman J, Miller J, Smith C. Consequences of exercise-induced respiratory muscle work. Respir Physiol Neurobiol 2006; 151: 242-50. [CrossRef]

7. Garrod R. The Effectiveness of pulmonary rehabilitation: evidence and implications for physiotherapists. London: Kingston University Press 2003. 
8. Massery M. Chest development as a component of normal motor development: implications for pediatric physical therapists. Chest Development 1991; 3-8.

9. Rochester D. Respiratory effects of respiratory muscle weakness and atrophy. Am Rew Respir Dis 1986; 134: 1083-6.

10. Park ES, Park JH, Rha DW, Park C, Park CW. Comparison of the ratio of upper to lower chest wall in children with spastic quadriplegic cerebral palsy and normally developed children. Yonsei Med J 2006; 47: 237-42. [CrossRef]

11. Seddon PC, Khan Y. Respiratory problems in children with neurological impairment. Arch Dis Child 2003; 88: 75-8. [CrossRef]

12. Strauss D, Cable W, Shavelle R. Causes of excess mortality in cerebral palsy. Dev Med Child Neurol 1999; 41: 580-5. [CrossRef]
13. Muammer K, Muammer R. Pulmonary rehabilitation and encountered difficulties in disabled children. Yeditepe Medical J 2009; 11 : 220-6.

14. Kwon YH, Lee HY. Differences of respiratory function according to level of the gross motor function classification system in children with cerebral palsy. J Phys Ther Sci 2014; 26: 389-91. [CrossRef]

15. Kwon YH, Lee HY. Differences of the truncal expansion and respiratory function between children with spastic diplegic and hemiplegic cerebral palsy. J Phys Ther Sci 2013; 25: 1633-5. [CrossRef]

16. Alexander R, Boehme R, Cupps B. Normal development of functional motor skills: the first year of life. Tucson, Ariz: Therapy Skill Builders 1993. 